\title{
Neurodevelopmental outcomes of a 25 - week premature infant at three years of age
}

\author{
Eileen R. McGrath* \\ Department of Pediatrics, College of Medicine, The University of Arizona, USA
}

\section{Introduction}

Extremely preterm infants (22 - 28 weeks gestation) are at high risk of morbidity and death. In a population-based study, Anderson and colleagues determined that twenty-eight percent of all extremely preterm infants died within the first year of life. Among infants born at 22,23 , and 24 weeks, survival to one year of age was $6 \%, 27 \%$, and $60 \%$, respectively and increased further for each 1 -week increase in gestational age, from $78 \%$ at 25 weeks to $94 \%$ at 28 weeks [1]. This report examines a surviving premature neonate at three years of age to report his neurological outcomes.

Major neonatal morbidities are common for survivors of preterm births. These include sepsis, periventricular leukomalacia, intraventricular hemorrhage, bronchopulmonary dysplasia, necrotizing enterocolitis, retinopathy of prematurity, chronic lung disease, cerebral palsy, severe visual impairment and hearing impairment. Although survival rates for extremely low birth weight premature infants have improved, rates of neonatal morbidity remain high. Infants discharged from a Newborn Intensive Care Unit after a lengthy hospitalization have much higher rates of re-hospitalizations during their first year of life than their full term peers [2].

Bronchopulmonary dysplasia is a serious complication of preterm birth and is more common in infants with low birth weight and in those who have received prolonged mechanical ventilation or supplemental oxygen to treat acute respiratory distress syndrome. A lower gestational age at delivery, especially 26 weeks or less, results in extreme structural and biochemical lung immaturity which is the most powerful risk factor for the development of bronchopulmonary dysplasia [3]. Infants who have had bronchopulmonary dysplasia are at greater risk for repeated respiratory infections such as bronchiolitis, influenza, respiratory syncytial virus and pneumonia. Other complications of bronchopulmonary dysplasia can include poor growth and developmental problems. Poor growth and development is a common problem in premature neonates and is often associated with subsequent neurodevelopmental delays. These neonates are frequently discharged from the hospital with significant growth deficits and show reduced rates of growth throughout childhood [4]. This observed growth lag has been associated with neurological and sensory handicaps and poor school performance [5]. The lifelong injury associated with prematurity is exaggerated in the setting of a history of bronchopulmonary dysplasia. The severity of the pulmonary dysfunction seems to persist throughout life, with clear separation between extremely low birth weight infants with bronchopulmonary dysplasia and those without [6].

The neurologic sequelae of prematurity and its treatment reveal life-long structural and functional impairments. Injury to the brain correlates highly with gestational age just as it does with the lungs. Even with the dramatic changes in medical management over the last several decades, the rates of neurodevelopmental abnormalities among preterm infants remains high [5]. Kobaly and colleagues have documented that even with changes in clinical practices between 2000 and 2003, neurodevelopmental outcomes did not improve compared with earlier eras and that premature infants with bronchopulmonary dysplasia continue to have poorer cognitive performance compared with children born prematurely who did not develop bronchopulmonary dysplasia [6,7]. Children who are born prematurely are at risk for reduced cognitive test scores and their immaturity at birth is directly proportional to the mean cognitive scores at school age. Children born preterm also show an increased incidence of attention deficit hyperactivity disorder and other behaviors [8].

One of the most common cardiac problems premature babies experience is a patent ductus arteriosus. This heart defect occurs soon after birth in some neonates. In patent ductus arteriosus, abnormal blood flow occurs between two of the major arteries connected to the heart. Prior to birth, the aorta and the pulmonary artery are connected by a blood vessel called the ductus arteriosus, which is an essential part of fetal blood circulation. Within minutes, or up to a few days after birth, the ductus arteriosus is supposed to close as part of the normal changes that occur in a neonate's circulation. However, in some infants the ductus arteriosus remains patent (open). The opening allows oxygen-rich blood from the aorta to mix with oxygen-poor blood from the pulmonary artery, which can strain the heart and increase blood pressure in the lung arteries.

\section{Patient presentation}

This three-year-old white male born at 25 weeks gestation to a 24-year-old, gravida 3, para 0 white female was hospitalized in a Newborn Intensive Care Unit (NICU) for 127 days. Maternal history was significant for two prior pregnancy losses, left salpingectomy and umbilical hernia repair. Mother was admitted for pre-term labor, urinary tract infection and chorioamnionitis. Rupture of the membranes occurred artificially on the day of delivery and this male infant was delivered vaginally. Initially, he was pale, had a heart rate greater than 100, poor tone and exhibited no respiratory effort. The neonate was given positive pressure ventilation that resulted in an

Correspondence to: Eileen R. McGrath, Ph.D., Department of Pediatrics, College of Medicine, The University of Arizona, PO Box 245073, Tucson, AZ 85724, USA, Tel: (520) 626-6548, Fax: (520)626-2808, E-mail: ermcgra@ peds.arizona.edu

Received: August 05, 2017; Accepted: August 30, 2017; Published: September 02, 2017 
improvement in his respiratory and heart rates. By five minutes of life he had improved color and tone and spontaneous respirations. The infant had Apgar scores of 5, 6 and 8 at 1,5, and 10 minutes respectively. He was admitted into the NICU on continuous positive airway pressure. After admission, he continued to experience respiratory distress requiring intubation and surfactant administration. The infant transitioned from mechanical ventilator to nasal positive pressure ventilation. There were concerns for volume overload as the infant had fluctuation in his supplementary oxygen need and difficulty weaning respiratory support. After administration of diuretics on day of life 56, his respiratory status improved and he was weaned to high-flow nasal cannula and then to regular nasal cannula. He was discharged home on 0.1 liters oxygen via nasal cannula. He remained on home oxygen through eight months adjusted age.

An echocardiogram performed on day of life 15 demonstrated a patent ductus arteriosus with left-to-right shunt. During this time the infant was requiring increased respiratory support and had a slight metabolic acidosis. He was started on indomethacin in an effort to close the patent ductus arteriosus. A repeat echocardiogram revealed that the patent ductus arteriosus remained patent; however, it had decreased in size. Several days later the infant had an increase in bradycardic and desaturation episodes and a repeat echocardiogram demonstrated a persistent moderate patent ductus arteriosus with left to right shunt. $\mathrm{He}$ received a second course of indomethacin and repeat echocardiogram following this treatment revealed a patent ductus arteriosus that was small in size. An echocardiogram was repeated prior to discharge and demonstrated a small restrictive patent ductus arteriosus and patent foramen ovale with left to right atrial level shunt. At three years of age, the patent ductus arteriosus and the patent foramen ovale continue to be present.

A head ultrasound was performed at one week of life and revealed a left grade 1 germinal matrix hemorrhage. Repeat ultrasound at one month of life demonstrated interval resolution of the hemorrhage. Additionally, he failed his newborn hearing screening two times prior to discharge; however at six months adjusted age he passed an audiological evaluation.

Gastroesophageal reflux disease and poor respiratory status resulted in feeding difficulties for this infant. He began nippling $20 \%$ percent of his feeds on day of life 71; however, the following week, after multiple episodes of apnea and bradycardia, he stopped nippling all feeds. He was placed in a Danny sling to aid in the reduction of reflux and to facilitate improvement in feeding. At 34 weeks adjusted age, physical therapy services in the NICU were started providing daily opportunities for positioning, infant massage, floor-time, and parent education. With the onset of physical therapy, this male infant showed rapid improvement in feeding, nippling $45-75 \%$ of his feeds. Post-discharge, formulas were reassessed and continually altered due to ongoing difficulties with reflux.

Table 1 identifies the medical problems experienced by this 25 week premature infant, the medications prescribed and the medical problems that remained active at discharge. At three-years of age these medical conditions remain active.

Follow-up appointments post-discharge throughout his first three years of life included pulmonology, cardiology, ophthalmology, and developmental follow-up clinics. He continued to see a pediatric surgeon who monitored a fluid pocket formed after his inguinal hernia surgery. He received occupational, physical, and speech therapy twice monthly in two different environments through the state's Early Intervention Program beginning at five months postdischarge and continuing through three years of age when he aged out of early intervention services and did not qualify for preschool special education through the local school district. Occupational therapy focused on feeding and sensory issues associated with hypersensitivity to sound, touch and vestibular stimuli.

This child was seen in the developmental follow-up clinic at the adjusted ages of: 5 months, 1 day ( 8 months, 15 days chronological); 10 months, 3 days (13 months, 17 days chronological); 16 months, 17 days (20 months chronological); and at 26 months, 15 days and 32 months, 21 days chronological age. The Test of Infant Motor Performance (TIMP) was performed during his initial visit at two months adjusted and the Bayley Scales of Infant and Toddler Development (Bayley III) [9] were administered during each subsequent evaluation.

Neurodevelopmental disability related to cognition, motor and language is often categorized by the Bayley-III, which is a tool used to quantify developmental outcome during the first three years of life. The Bayley-III is an individually administered instrument that assesses the developmental functioning of infants and young children 1 month to 42 months of age and consists of three administered scales: the Cognitive Scale, the Language Scale (receptive and expressive language subtests) and the Motor Scale (gross motor and fine motor subtests). This assessment enables practitioners to compare a child's performance with same-age peers and identify the areas of development that appear responsible for any delay in development.

The types of available quantitative scores include: Raw Scores, Derived Scores and Norm-referenced Scores. A raw score is the sum of the number of points earned for each subtest. Derived scores and norm-referenced scores include: scaled scores, composite scores, percentile ranks, developmental age equivalents, and growth scores. Scaled scores, which are derived from the raw scores, represent a child's

Table 1. Clinical data on case

\begin{tabular}{|c|c|c|c|}
\hline & Medical problems & Medications & Active problems at discharge \\
\hline $\begin{array}{l}\text { Male: } 256 / 7 \text { weeks } \\
\text { Birth weight: } 995 \mathrm{~g}\end{array}$ & $\begin{array}{l}\text { (1) Neonatal Abstinence Syndrome } \\
\text { (medically induced) } \\
\text { (2) Acute Respiratory Distress Syndrome / } \\
\text { Chronic Lung Disease with hypoxia } \\
\text { (3) Bleed to brain -Spontaneous } \\
\text { Intraparenchymal Intracranial } \\
\text { Hemorrhage presume germinal matrix } \\
\text { (4) Congenital Heart Disease } \\
\text { (5) Apnea prematurity } \\
\text { (6) Gastroesophageal Reflux disease } \\
\text { (7) Retinopathy of Prematurity } \\
\text { (8) Patent ductus arteriosus (PDA) } \\
\text { (9) Inguinal hernia } \\
\text { (10)Eczema }\end{array}$ & $\begin{array}{l}\text { Albuterol sulfate (Proventil) } 2.5 \mathrm{mg} / 0.5 \mathrm{~mL} \\
\text { Nebulizer } \\
\text { Hydrocortisone } 1 \% \text { cream } \\
\text { Ranitidine HCI } 15 \mathrm{mg} / \mathrm{mL} \\
\text { Triamcinolone (Kenalog) } 0.1 \% \text { cream } \\
\text { Pediatric Multivitamin (Poly-Vi-Sol) }\end{array}$ & $\begin{array}{l}\text { (1) Chronic Lung Disease } \\
\text { (2) Anemia of Prematurity } \\
\text { (3) Bronchopulmonary Dysplasia (BPD) } \\
\text { (4) Patent ductus arteriosus (PDA) } \\
\text { (5) Patent Foramen Ovale (PFO) }\end{array}$ \\
\hline
\end{tabular}


performance on a subtest relative to his or her same aged peers. These scores are scaled to a metric with a range of 1 to 19 , a mean of 10 , and a standard deviation $(S D)$ of 3 . A subtest scaled score of 10 reflects the average performance of a given age group. Scores of 7 and 13 are equivalent to $1 S D$ below and above the mean, respectively, and scores of 4 and 16 are equivalent to $2 S D$ from the mean [10].

Composite scores, often described in more qualitative terms according to a child's level of performance, can be characterized as falling within a certain level of performance (e.g., Scales: Very Superior, Superior, High Average, Average, Low Average, Borderline, and Extremely Low). A score of 100 on any of the composites defines the average performance of a given age group, and scores of 85 and 115 are $1 S D$ below and above the mean, respectively. Bayley-III scaled and composite scores provide the most accurate description of test data [9]. Data reveal that the Bayley-III is a very reliable instrument and that one can have a high level of confidence in the scores a child obtains on this test. Data also provide empirical support for the five scales of the Bayley-III. Each item was found to have a higher correlation with the scale in which it is placed than with the other scales [11].

Table 2 gives the scaled and composite scores for each developmental follow-up clinic visit from 5 months, 1 day adjusted through 32 months, and 21 days. Although scaled and composite scores fell within the average range, this infant presented with acquired plagiocephaly during his evaluation at 5 months, 1 day adjusted age. Cranial banding was recommended and the infant was evaluated for a helmet. Re-establishment of weekly physical therapy and occupational therapy was also recommended and a referral was made for the family.

The Bayley III evaluation completed at 10 months, 3 days again resulted in average scaled and composite scores in all five areas of development. The infant had been wearing a helmet for three months and was receiving bi-monthly occupational and physical therapy. Additionally, mother reported that, on a daily basis, she was engaged in the reading, play, motor and language recommendations made by the developmental follow-up team.

At the adjusted age of 16 months, 17 days (20 months chronological) he excelled in cognitive and fine motor skill development and continued to make good progress in expressive language and social skills development. At 26 months, he was no longer wearing the helmet and was engaged in sustained toe walking. It was recommended that physical therapy address vestibular and multi-sensory stimulation to assist with improved walking pattern, balance, and to prevent range of motion restrictions. Mother reported that the pediatrician recommended the use of a walker and jumper; she was counseled regarding the potential negative outcomes of use (restricted range of motion, habitual toe walking, instability, delayed gross motor development). His activity level was very high at this time but he could be re-directed to complete activities. Six months later, this 32 month old males' Composite scores fell in the Superior (Total Motor) and High Average (Cognition and Total Language) ranges and Scaled scores were 1 to 3 Standard Deviations (SD) above the mean (Table 2).

\section{Discussion}

High-risk premature infants often experience medical problems following discharge from Newborn Intensive Care Units. Increasing numbers of premature infants are being sent home on oxygen, gastrostomy and nasogastric tubes, high calorie formulas and apnea monitors [12]. Post-discharge morbidities for these high-risk infants often include respiratory illnesses, feeding problems, failure to thrive, anemia and neurodevelopmental disabilities. The National Institute of Child Health and Human Development recommends follow-up for all infants with a birth weight of 1000 grams or less with assessment of their socioeconomic status, family resources, growth, neurologic status, behavior and language [2]. Newborn developmental followup clinics provide an important resource for optimizing care of these specialized and often complicated children by identification of neurodevelopmental status, deviations of growth and behavior.

This 25-week Newborn Intensive Care Unit graduate was seen in follow up in an academic setting throughout his first three years of life. After discharge from the NICU, he was evaluated twelve times in three years for severe respiratory complications. The status of his patent ductus arteriosus and patent foramen ovale were assessed, annually, and he continued to see ophthalmology each year following retinopathy of prematurity. He was hospitalized five times for up to four days for each encounter for bronchopulmonary dysplasia, respiratory syncytial virus, influenza and pneumonia. He has continued to follow up with surgeon twice annually. Additionally, he was seen in the neonatal developmental follow-up clinic approximately every six months until 32 months of age.

Although there was little variation in the Bayley III Scaled and Composite scores from five months adjusted to 32 months of age, the receptive language Scaled and Composite scores at 26 months placed his total language score at one standard deviation (1 SD) below the mean. The regression in language skill development coincided with a change in family dynamics and hospitalizations for influenza and pneumonia. Within six months he made significant gains in both receptive and expressive language development scoring above average with a total language score of one standard deviation above the mean.

Concerns have been raised about assessing cognitive and language development with the Bayley III [13-16]. Reports highlight the potential underestimation of developmental delays by the Bayley III

Table 2. Scaled and composite scores on the Bayley scales of infant toddler development (Bayley III). Standard Deviations (SD) are indicated

\begin{tabular}{|c|c|c|c|c|c|}
\hline $\begin{array}{l}\text { Adjusted age through } 24 \\
\text { months }\end{array}$ & 5 months, 1 day & 10 months, 3 days & 16 months, 17 days & 26 months, 15 days & $\begin{array}{l}32 \text { months, } \\
21 \text { days }\end{array}$ \\
\hline Cognitive & $\begin{array}{c}12 / 110 \\
2 / 3 \text { SD Above Mean }\end{array}$ & $\begin{array}{c}11 / \mathbf{1 0 5} \\
\text { 1/3 SD Above Mean }\end{array}$ & $\begin{array}{c}16 / 130 \\
2 \text { SD Above Mean }\end{array}$ & $\begin{array}{c}11 / \mathbf{1 0 5} \\
\text { 1/3 SD Above Mean }\end{array}$ & $\begin{array}{c}15 / \mathbf{1 2 5} \\
1 \& 2 / 3 \text { SD Above Mean }\end{array}$ \\
\hline Receptive Communication & 12 & 12 & 11 & 7 & 13 \\
\hline Expressive Communication & 9 & 10 & 10 & 10 & 13 \\
\hline Total Language & $\begin{array}{c}103 \\
\text { Mean }\end{array}$ & $\begin{array}{c}106 \\
\text { 1/3 SD Above Mean }\end{array}$ & $\begin{array}{c}103 \\
\text { Mean }\end{array}$ & $\begin{array}{c}91 \\
1 \text { SD Below Mean }\end{array}$ & $\begin{array}{c}118 \\
1 \text { SD Above Mean }\end{array}$ \\
\hline Fine Motor & 12 & 10 & 18 & 12 & 16 \\
\hline Gross Motor & 11 & 11 & 10 & 17 & 19 \\
\hline Total Motor & $\begin{array}{c}110 \\
\text { 2/3 SD Above Mean }\end{array}$ & $\begin{array}{c}103 \\
\text { Mean }\end{array}$ & $\begin{array}{c}124 \\
1 \& 2 / 3 \text { SD Above Mean }\end{array}$ & $\begin{array}{c}127 \\
1 \& 2 / 3 \text { SD Above Mean }\end{array}$ & $\begin{array}{c}145 \\
3 \text { SD Above Mean }\end{array}$ \\
\hline
\end{tabular}


Scales of Infant and Toddler Development. However, it has not yet been determined whether the Bayley III underestimates developmental delay or whether the earlier version, the Bayley II, overestimated it.

A number of factors may have been responsible for enhancing the developmental outcomes for this child during his first 32 months of life. The increased long-term neurodevelopment, learning and adaptive outcomes could be due to some, or a combination of such factors as: developmental care intervention in the earliest stages of his development, parent participation and follow-through on developmental interventions in the NICU and with bimonthly therapy sessions and developmental follow-up clinic, parental engagement with child in developmental play activities, family support and environmental factors.

The neonatal care delivered over the 127 days of his hospitalization, used neuroprotective interventions as strategies to support optimal synaptic neural connections, promote normal development, and prevent disabilities. The neuroprotective measures taken for familycentered developmental care of this extremely preterm neonate, generally referred to as the neonatal integrative developmental care model, included: positioning and handling, partnering with the family, minimizing stress and pain, safeguarding sleep, optimizing nutrition, protecting the skin and maintaining a healing environment [17]. The mother was at bedside participating in his care on a daily basis. She engaged in regular kangaroo mother care, daily rounds and physical and occupational therapy consultations.

Research shows that kangaroo care improves bonding with parents which reduces stress in parents and positively impacts the neonates' brain and emotional development. It can help premature infants regulate their heart rate, temperature and breathing and stabilize their organ function and improve self-regulation [18]. Kangaroo mother care has been shown to have significant, long-lasting social and behavioral protective effects 20 years after intervention [19]. Although this child is only three years old at this reporting, these benefits could have impacted his early development.

While development is a complex and multi-dimensional process, we do know that the family unit plays a fundamental role in a child's development. Family involvement helps to minimize the effects of perinatal damage, primarily through the participation of parents in the care of the child. Furthermore, paternal involvement has been shown to be important in the early development of infants. In this case, however, the lack of paternal involvement due to incarceration, did not appear to have a negative impact on this child's development. Abnormalities or deviations cannot be explained by any single protective or risk factor; however, the quality of the intensive care and subsequent home environment played a critical role in the trajectory or recovery, growth and development for this extremely pre-term infant.

\section{Acknowledgement}

This work was supported, in part, by a grant from the Health Resources Services Administration (HRSA) Maternal and Child Health Bureau (MCHB) Leadership Education in Neurodevelopmental Disabilities Grant \#T73MC20662.

\section{References}

1. Anderson JG, Baer RJ, Partridge JC, Kuppermann M, Franck LS, et al. (2016) Survival and Major Morbidity of Extremely Preterm Infants: A Population-Based Study. Pediatrics 138. [Crossref]

2. Bockli K, Andrews B, Pellerite M, Meadow W (2014) Trends and challenges in the United States neonatal intensive care units follow-up clinics. J Perinatol 34: 71-74. [Crossref]

3. Kim JK, Chang YS, Sung S, Ahn SY, Yoo HS (2016) Trends in survival and incidence of bronchopulmonary dysplasia in extremely preterm infants at 23-26 weeks gestation. J Korean Med Sci 31: 423-429. [Crossref]

4. Fewtrell MS1 (2003) Growth and nutrition after discharge. Semin Neonatol 8: 169-176 [Crossref]

5. Clark RH, Thomas P, Peabody J (2003) Extrauterine growth restriction remains a serious problem in prematurely born neonates. Pediatrics 111: 986-990. [Crossref]

6. Glass HC, Costarino AT, Stayer SA, Brett CM, Cladis F, et al. (2015) Outcomes for extremely premature infants. Anesth Analg 120: 1337-1351. [Crossref]

7. Kobaly K, Schluchter M, Minich N, Friedman H, Taylor HG, et al. (2008) Outcomes of extremely low birth weight $(<1 \mathrm{~kg})$ and extremely low gestational age $(<28$ weeks $)$ infants with bronchopulmonary dysplasia: effects of practice changes in 200 to 2003. Pediatrics 12: 73-81

8. Bhutta AT, Cleves MA, Casey PH, Cradock MM, Anand KJ (2002) Cognitive and behavioral outcomes of school-aged children who were born preterm: a metaanalysis. JAMA 288: 728-737. [Crossref]

9. Bayley N (2006) Bayley Scales of Infant and Toddler Development. ( $3^{\text {rd }}$ Edn). San Antonio, TX: Harcourt Assessment Inc.

10. Bayley N (2006) Technical Manual: The Bayley Scales of Infant and Toddler Development-Third Edition. San Antonio, TX: The Psychological Corporation.

11. Hatton DD, Bailey DB, Burchinal MR, Ferrell KA (1997) Developmental growth curves of preschool children with vision impairments. Child Development 68: 788-806.

12. Kuppala VS, Tabangin M, Haberman B, Steichen J, Yolton K (2012) Current state of high-risk infant follow-up care in the United States: Results of a national survey of academic follow-up programs. J Perinatol 32: 293-298. [Crossref]

13. Chong JLY, Anderson PJ, Burnett AC, Roberts G, Davis N, et al. (2017) Changing neurodevelopment at 8 years in children born extremely premature since the $1990 \mathrm{~s}$. Pediatrics 139: e20164086.

14. Anderson PJ, De Luca CR, Hutchinson E, Roberts G, Doyle LW, et al. (2010) Underestimation of developmental delay by the new Bayley-III scale. Arch Pediatr Adolesc Med 164: 352-356. [Crossref]

15. Moore T, Johnson S, Haider S, Hennessey E, Marlow N (2012) Relationship between test scores using the second and third editions of the Bayley Scales in extremely premature children. J Pediatr 160: 553-558. [Crossref]

16. Spencer-Smith MM, Spittle AJ, Lee KJ, Doyle LW, Anderson PJ (2015) Bayley-III Cognitive and Language Scales in Preterm Children. Pediatrics 135: e1258-1265. [Crossref]

17. Altimier L, Phillips R ((2016) The neonatal integrative developmental care model Advanced clinical applications of the core measures for neuroprotective family-centered developmental care. Newborn \& Infant Nursing Reviews 16: 230-244. [Crossref]

18. World Health Organization. (1993). Kangaroo mother care: a practical guide. Retrieved July 12, 2013 from http://www.who.int/maternal child adolescent/ documents/9241590351/en/

19. Charpak N, Tessier R2 Ruiz JG, Hernandez JT, Uriza F, et al. (2017) Twenty-year Follow-up of Kangaroo Mother Care Versus Traditional Care. Pediatrics 139. [Crossref]

Copyright: C2017 McGrath ER. This is an open-access article distributed under the terms of the Creative Commons Attribution License, which permits unrestricted use, distribution, and reproduction in any medium, provided the original author and source are credited. 